\title{
Shark and ray genomics for disentangling their morphological diversity and vertebrate evolution
}

Shigehiro Kuraku ${ }^{1,2,3}$

${ }^{1}$ Department of Genomics and Evolutionary Biology, Molecular Life History Laboratory, National Institute of Genetics

${ }^{2}$ RIKEN Center for Biosystems Dynamics Research, Laboratory for Phyloinformatics ${ }^{3}$ Correspondence: skuraku@nig.ac.jp

May 26, 2021

\section{Hosted file}

MS-SharkGenome-forAuthorea.pdf available at https://authorea.com/users/386789/articles/ 523646-shark-and-ray-genomics-for-disentangling-their-morphological-diversity-andvertebrate-evolution 